\title{
Where there was one, now there are two
}

\author{
Christopher Price ${ }^{1}$ and Greg FitzHarris ${ }^{2}$ \\ ${ }^{1} C R R F$, Department of Veterinary Biomedicine, University of Montreal, Quebec, Canada and \\ ${ }^{2}$ CRCHUM, Department of OBGYN, and CRRF, University of Montreal, Quebec, Canada
}

Correspondence should be addressed to C Price; Email: christopher.price@umontreal.ca or to G FitzHarris;

Email: greg.fitzharris@umontreal.ca

Reproduction (2018) 155 E1

Under the expert guidance of outgoing Editor-in-Chief, Prof. Kevin Sinclair, Reproduction has gone from strength to strength with the number of submissions increasing $31 \%$ over the last 5 years. Perhaps the most obvious impact of this popularity is the appointment of two new Editors-in-Chief instead of one. Prof. Christopher Price is a long-time member of the Society for Reproduction and Fertility (SRF), having joined in 1984, and has served on the Editorial Board of Reproduction for eight years. Dr Greg FitzHarris has been a member of SRF since 2001 and has been on the journal Editorial Board for 6 years. The Editors-in-Chief are at the Faculty of Veterinary Medicine and the Faculty of Medicine, University of Montreal, respectively. We continue to have an editor dedicated to the Reviews section of the journal, and we are pleased that Dr Trudee Fair, University College Dublin, has taken over this role.

The incoming senior editorial team highlights the international nature of the journal; the journal is owned by SRF and published by Bioscientifica in the United Kingdom, the Editors-in-Chief are in Canada, the Reviews Editor is in Ireland. The Editorial Board is also very international, with 12 North American, 17 European, 3 Australasian and 2 South American board members.

The mission of Reproduction has been and remains the publication of high-quality research in reproductive biology, irrespective of species. We welcome research that is mechanistic, of a clinical nature, or descriptive, but all studies must demonstrate a clear advance in our understanding of biological principles. We are also encouraging submissions in the fields of reproductive immunology, reproductive toxicology and developmental biology. The advantages to publishing in Reproduction include a fast time to first response (mean of 20 days), no publication charges and free colour images. Reproduction also prides itself in a clear and user-friendly review process, with clear guidance to authors on how and why decisions are made.

We are excited by recent new initiatives for the journal, including 'anniversary issues', the first of which marked the 30th anniversary of the discovery of interferon-tau guest-edited by Prof. Michael Roberts and appeared in the November 2017 issue, and the second, to celebrate 25 years of ICSI, was published in the December issue. The next anniversary issue will mark the 40th anniversary of the birth of the first IVF baby, and we are pleased that Professor Lord Robert Winston is guest-editing this issue, which will be published this spring. Another new initiative is in-article videos, which allows authors to embed video clips into their online articles; an example can be viewed here (http://www.reproduction-online. org/content/155/1/R63.full\#DC1). Finally, this year saw the presentation of the first Reproduction Prize at the Fertility 2018 conference in Liverpool UK. This prize will be offered on a yearly basis and will recognize the best paper published in Reproduction during the preceding year, the winner receiving free registration and travel to attend the annual Fertility meeting to present their paper to the conference. To mark the transition, the new Co-Editors-in-Chief have each contributed a review article, which appears in this current issue. An informal interview to introduce Chris and Greg to the readers can be found here (http://www.reproduction-online. org/content/155/1/E1/suppl/DC1). We encourage you to submit your best work to Reproduction!

Received 12 October 2017

Accepted 23 October 2017 